\title{
A Study of Hospitality Internship in Gokarna Forest Resort, Nepal
}

\author{
Ramesh Raj Kunwar* \\ Sarswati Khatri-Thapa**
}

\begin{abstract}
Hospitality and Tourism industry and internship are crucial to each other and for this reason, the industry as well as the prospective intern should be fully aware about the internship and its various aspects. To make the internship more effective it should be studied from the perspective of prospective interns and the employer. Because of the lack of adequate understanding the interns as well as the employers are facing the difficulties when the internship starts. This article tries to present an internship from various perspectives as well as portray an intern's change of understanding about the internship before and after the involvement in the field. This portray mainly focus on the concept of internship, knowledge before, during and after internship, learning experience, difference between theoretical and real life world with some suggestions for the following generations.
\end{abstract}

Keywords: hospitality, internship, cultural competence, knowledge exposure, emotional labor

\section{Introduction}

The word Hospitality has been tried to be described in many different ways by many people and scholars. These definitions have been based on the distinction between the pure hospitality and commercial hospitality and to understand the concept of hospitality both perspective should be given equal attention. The Oxford English Dictionary (2002; in Hemmington, 2007:8 ) defines hospitality as the 'friendly and generous reception of guests or strangers', while the Chambers English Dictionary (2001; in Hemmington, 2007:8) defines it as, 'entertaining strangers

\footnotetext{
* Prof. Dr. Ramesh Raj Kunwar is the author of seven books on tourism and anthropology. He is tourism educationist and anthropologist by profession. He is the former Dean of Faculty of Humanities and Social Sciences, Tribhuvan University, Kathmandu, Nepal. He is also the former Dean of (then) Royal Nepalese Military Academy. Currently, he is teaching at the Department of Cunflict, Peace and Development Studies (DCPDS), T.U. Email: kunwardr@gmail.com

** Sarswati Khatri-Thapa completed Bachelor Degree in Hospitality and Tourism Management from Nepal College of Management affiliated to Kathmandu University. Email: sarswatikhatri22@gmail.com
} 
and guests kindly and without reward: showing kindness: generous: bountiful'. As Lashley (2000; in Hemmington, 2007:8) states, 'hospitality requires the guest to feel that the host is being hospitable through feelings of generosity, a desire to please and a genuine regard for the guest as an individual. Laskley (2000; in Hemmington, 2007:9 ) states that, 'hospitality is essentially a relationship based on hosts and guests' and it is the host-guest relationship that is the key distinguishing characteristic of hospitality from which several other dimensions emerge (Pritchard, 1981; Stringer 1981; in Hemmington, 2007:9).

Since 1998 hotel management study in Bachelor level was started in Nepal. Majority of the students did intern in Nepal, India, Malaysia, Dubai, China, Thailand and some other countries. Approximately every year 1500-2000 students go for internship for minimum 6 months to maximum 1 year. According to university system, every students have to write intern report and they have to submit the report to their respected colleges. Though some reports are published in the academic journals, by the foreign students (Yafang \& Gongyong, n.d.; Walo, 2000; Kim, 2008; Abdullah, Zahari, Mat, Zain \& Derani, 2015) no reports are published in the context of Nepalese internship yet. Therefore, this is going to be first effort making an academic paper in the field of tourism and hospitality internship in Nepal. This work will be very useful for the future generations for understanding hospitality internship in better way. The internship was carried out in Gokarna Forest Resort in Kathmandu Valley, Rajnikunj Thali for six months (March $1^{\text {st }}$ to August 31st). The report was first submitted to the Nepal College of Management (NCM) affiliated with Kathmandu University (KU) as a requirement for the completion of bachelor degree. The aim of this research was to examine issues related to career expectations, assumptions and requirements of undergraduates of a bachelor hospitality management and the hospitality industry. Later on, the report has been revised with the support of several published academic literatures of tourism and hospitality and with a certain modification on theoretical base.

Hospitality involves hosts sharing their home with strangers and at the same time accepting responsibility for their safety, welfare and happiness. "If this is a host's task, it is concerned with more than food, drink and shelter: it means that a host must try to cheer up a miserable guest, divert a bored one, care for a sick one" (Telfer, 2000). However, the key responsibility of the host is to ensure the safety and well-being of the guest while he or she is in the host's home.

In the academic world, the dominant approach is one based on business and management, with many institutions focusing on services and some taking a retailing perspective. Jones (2002a; in Hemmington, 2007:3) sought to identify the "principal schools of thought" and identified six main approaches: science, management, studies, relationships, systems, and pragmatism. However, as Morrison \& O’Mahoney (2002; 
in Hemmington, 2007:3) state, there are "some major tensions, contradictions and debates confronting contemporary hospitality management educationalists", and that hospitality management as a field of study "continues to struggle for definition". This failure to understand the phenomenon of commercial hospitality acts a significant barrier to industry improvement (Wood 1992; in Hemmington, 2007:3), customer satisfaction and therefore growth.

Brotherton and Wood (2000; in Hemmington, 2007:5-6) offer a definition of hospitality: 'A contemporaneous human exchange, which is voluntarily entered into, and designed to enhance the mutual well being of the parties concerned through the provision of accommodation, and/or food, and/or drink' which, despite their claim that it 'captures the generic essence of hospitality', actually fails to capture any sense of the exciting, vibrant and creative industry in the real world. As Slattery (2002; in Hemmington, 2007:6) states, this is a, 'denuded and sterile conception of commercial hospitality and hospitality management'.

It commenced life with a focus on hospitality management, defined by Brotherton and Wood (2000: 168; in Morrison \& Gorman, 2008) as: 'the management of hospitality in that one set of intellectual constructs and practices (management) are applied to another (hospitality)'. Over time emerged a more inclusive hospitality studies approach which reflects on the connection of hospitality to society as a whole and the location of the world of business and management therein (Lashley et al., 2007; in Morrison \& Gorman, 2008). This stance embraces literature and theory of multiple genre and discipline, including the social sciences. Further, it supports reciprocal application between the intellectual constructs and practices of both hospitality, and business and management.

As Morrison \& O’Mahony (2003: 39; in Morrison \& Gorman, 2008) highlight, through such partnering there is: 'potential to generate new ways of thinking and a wider appreciation of world views on the concept of hospitality as broadly conceived'.

As stated by Davis (1990; in Morrison \& Gorman, 2008), internship is a kind of experiential learning where students take the opportunity to apply learned theories from schools in the real world situation, and it provides an opportunity for students to integrate and consolidate thinking and action. Statler, the father of the American hotel, who emphasized the need for hospitality students to experience the demands of management in the real world via a "hands-on" learning experience (Cited from Zopiatis, 2007; in Morrison \& Gorman, 2008).

Within this higher education context, the academic subject of hospitality management has been defined by the Higher Education Funding Council for England (1998: 15; in Morrison \& Gorman, 2008) as being: 'characterized by a core which addresses the management of food, beverages and accommodation in a 
service context'. This explicit intention is to prepare students for an occupationally circumscribed profession on graduation.

In an effort to capture the essence of the hospitality studies, Morrrison and O'Gorman (2006:3; in Morrison \& Gorman, 2008) made a preliminary attempt to craft a working definition as follows:

It (hospitality) represents the cordial reception, welcome and entertainment of guests or strangers of diverse social backgrounds and cultures charitably, socially or commercially with kind and generous liberality, into one's home space to dine and lodge temporarily. Dependent on circumstance and context the degree to which the hospitality offering is conditional or unconditional may vary.

Thus, it is argued that the hospitality studies school of thought has the potential to contribute to 'the creation of new knowledge that is not merely wed to unitary business, industry and management ways of knowing what is hospitality.

Understanding the hospitality from commercial and non-commercial perspective provides a greater horizon for the people of this industry to understand the hospitality and apply its use with greater and distinct benefits. One of the most related terms to hospitality is internship which is the outcome of the blend of commercial hospitality and the requirement to be ready to face the challenge in the real world. With the hospitality industry is becoming more and more demanding the requirement to make the potential entrant to the industry ready to face the challenge is creating internship opportunity. Internship is a crucial part of the present highly flourishing hospitality industry. Because of its increasing importance it should be understood properly by the different players like the employers, prospective interns and others.

There is no argument that tourism and hospitality industries are regarded as 'people industries' and that effective management of these human resources is highly important. The delivery of high quality service can give an organisation a competitive edge and an organisation's human resources, particularly front-line employees, are crucial to future success (Umbreit, 1993; in Walo, 2000:10). There is widespread agreement amongst many tourism and hospitality researchers that, more soft human relation skills such as oral and written communication and interpersonal communication are essential skills for graduates and new trainees to possess (Okeiyi, Finley, and Postel, 1994; Richins, Tait, and Hamlin, 1994; Tas, LaBrecque, \& Clayton, 1996; Maes, Weldy, \& Icenogle, 1997; in Walo, 2000:10)). With the industries' need for strong human relation skills, educators must ensure that students have a clear understanding of the importance of these skills and are provided every opportunity to develop them throughout their degree program.

Moreover, management development through work experience can commence during university education. In fact a major issue for many researchers in tourism 
and hospitality management education is the role and benefit of experiential learning or practical work experience. There is consensus that practical work experience or internship is one of the most effective ways that students can apply the theory learnt in the classroom environment (Ford \& LeBruto, 1995; in Walo, 2000:11)

It appears there is substantial agreement between all stakeholders - employers, educators and students - that practical work experience is vital for the future success of tourism and hospitality management graduates (Breiter, 1991; in Walo, 2000:12)

Each component, namely internship performance, industrial training file completion, project and presentation of the project should be weighted accordingly. There is no better teacher than experience to allow students to "touch the stove", so to speak, enhance their formal learning curve and, in most instances, that curve turns up when industrial training is implemented. Education was never meant to be isolated in Ivory Tower, it must be embraced by those that are taught as relevant to life (Collins, 2002:96).

In very small terms "internship" is a "bridge" from classroom to workplace. It is an opportunity to test skills, and interests and career choices in real work situations while obtaining an edge on "inexperienced" job market competitors (Neuman, 1999; in Collins, 2002:93). Hite \& Belizi (1986; in collins, 2002:93) found that students view internships as valuable learning experience, for which they should receive academic credit, financial compensation, and earn a grade. They also feel that internship are more valuable than case teaching, that formal training should be at the beginning of internships and direct supervision present throughout finally students feel that internships may result in employment. Students without practical experience realize that they have disadvantage when compared to those with internship experience.

Internship is a very important opportunity for students with the exposure they get being a part of the industry. Before entering the industry as professionals' they get to know about environment and working procedures which they will use after. Also students can choose the area of their specialization after trying the various departments during the internship period. Many of the students view the internship as an opportunity of entering the professional world as they work hard to continue with organizations and internship also provides a bonding opportunity to have a bond with the prospective employer. If employed, interns require less training and less time adjusting, than do non-interns. Interns learn quickly and represent flexible economic resources (Nevett, 1986; Pianko, 1996; in Collins, 2002: 93).

From employers perspective internship is an opportunity to know and test their potential employee's attributes and determine whether or not they are applicable for the industry. Internship provides the pool of people from whom they can pick the best fit for the job and the organization. Also the internship now is a very good 
opportunity to make the manpower available in the hospitality and tourism industry by making the adjustment with the fluctuating demand in business.

Student internships are one of the most important indicators in determining the quality of undergraduate hospitality management programs. By improving industry relations, sharpening students' critical thinking skills, increasing their commitment, and providing experiential learning opportunities with administration support, internships help ensure appropriate placement of graduates (Assante, Huffman, \& Harp, 2010; in Kim \& Park, 2013:72). Internships are not easily defined due to their varied scopes and are mostly determined by the unique nature of a school's curriculum and resources as well as a corporation's operational policy (Zopiatis \& Constanti, 2007; in Kim \& Park, 2013:72).

An internship can provide participants with the opportunity of learning what the industry offers, which may be completely different from what they learn in the classroom, and can certainly influence a student's career choice either positively or negatively manner. Participants can obtain a realistic sense of job responsibilities required in the industry through the work they do as interns (Kozar, Horton, \& Gregoire, 2005; in Kim \& Park, 2013:72). Besides, internship experiences can enhance the individual's self-confidence and maturity. Such experience can raise the graduate's labor market value, along with their familiarity with professional practice (Busby, 2003; Gibson \& Busby, 2009; Busby \& Gibson, 2010; in Kim \& Park, 2013:72). Internship requirements, together with the industrial experiences of faculty and actual qualifications of the students, can contribute to the participants' future career success (Chi \& Gursoy, 2009; in Kim \& Park, 2013:72). Students aiming to join the hospitality and tourism industry should give careful consideration to the internship program in order to develop and enhance their level of management competence and remain adaptable to future careers in the industry (Walo, 2001; in Kim \& Park, 2013:72).

Internships can have a positive impact on students' overall perception of career development in related industries and can improve their future marketability. Thus, it is necessary to provide students with practical projects that can increase the satisfaction level with regard to their internship experiences (Ju, Emenheiser, Clayton, \& Reynolds, 1998; in Kim \& Park, 2013:72). Students who experienced internships before they began their formal careers were found to have stronger career goals for the industry than those who did not (Chuang \& Dellmann-Jenkins, 2010; in Kim \& Park, 2013:72). Positive perception of the industry as an intern can reinforce a student's aspiration to and prospects for a future career in the industry, whereas negative perception is likely to adversely affect aspirations (Zopiatis \& Constanti, 2007; in Kim \& Park, 2013:72). 
Successful learning and supportive administration at the college level are critical components of students' confidence regarding their future careers in the hospitality industry. In addition, the quality of training can contribute to improved satisfaction and desire to stay on the job (Ko, 2007; in Kim \& Park, 2013:72). From the employers' perspective, the value of cooperative education includes reinforcing students' selfconfidence and self-concept, improving social skills, enhancing practical skills and knowledge of the industry, providing employment opportunities, helping to obtain skills that are complementary to theoretical training, and familiarizing students with the processes of the labor market (Garavan \& Murphy, 2001; in Kim \& Park, 2013:72). Internships, which can be supported by proper career and placement services, enable college students to gain industry related experience, improve their networking skills in the industry, and increase the rate of job placement upon graduation (Chi \& Gursoy, 2009; in Kim \& Park, 2013:72).

Undergraduate students majoring in hospitality, however, may have unfavorable views on the quality of the internship in which they participated (Jenkins, 2001; in Kim \& Park, 2013:72). Internship students are usually placed in positions involving routine tasks and with limited responsibility and receive insufficient training because of the short period of the internship and a lack of resources available for such training. Organizations could provide student interns with training in safety, hygiene, and departmental operations as well as orientation for newcomers. Students complain that organizations do not provide interns with various practical training options useful to prepare for their future careers in the hospitality and tourism industry (Collins, 2002; in Kim \& Park, 2013:72).

Employee knowledge is one of the most important resources in service firms and is particularly significant in performing activities that require interaction, collaboration and communication with customers (Atuanene- Gima, 1996; Simron \&Hitt, 2002). Knowledge cab be considered as object, as interpretation, process or as relationship (Kakihara \& Sorensen, 2002; in Mistilis \& Sheldon, 2005:5)

In the tourism industry in a particular, improving human capital has become a priority, especially when considering that most workers in this sector are low -skilled (Hjalayer, 2002; Walsh et al., 2008). However, when knowledge is located in the minds of individuals rather than in technologies, structure or routines, the risk of losing organizational knowledge is greater due to staff turnover (Argote,1999). Most of the employees leave the organization either to apply for the higher post in more reputed organization than they are working now or they will fly abroad seeking better opportunities. They will gain few years experience and when they have required knowledge, skills and abilities to bring new innovation in an organization innovate unique way of providing service they will shift to other place for more benefits. Therefore, most of the organizations take internship as a probation period and if the 
intern perform well they will recruit them as an employee, so that they need not to invest on new personnel for training the new employee and when they are trained they left the organization. Therefore, in order to minimize that risk the internship is unpaid and provided with academic credit only.

The main objective of the internship project work exposure was to get hands-on experience of the real world organization. It also aimed at the development required to handle the day to day operations in an organization. It allowed the intern to be prepared for the upcoming corporate challenge by experiencing real time working environment.

In fact, the exposure during the internship promotes each student not only with relevant functional skills, but also with interpersonal communication skills. To cope with the challenging environment, internship naturally serves as a platform for gaining wider knowledge to perform effectively with working experience. As a whole the internship program grooms the graduates corporate culture, develops public relationship and provides an excellent working experience. For an individual, an internship is very helpful to expose interpersonal relationship that is the demand of every job, not only with boss, coworkers, and supervisors but also with every lower level staff members are the basic things for obtaining a successful and contended career.

The six month work experience in real business institutions supported the learning in the present intern with the idea that an internship is the way of learning managerial skills. It helps to develop the professional working habit and helps to be familiar with corporate cultures. It gives a direction and provides ideologies for solving the practical problems and make capable of taking the right decision at need.

\section{Objective of the Internship}

$>$ Participate in the real life working environment

$>$ Understand the procedure of the operation of the organization.

$>$ Know about the practical business working environment

$>$ Develop effective interpersonal skills

$>$ Build professional contacts or develop networking

$>$ Develop professional skills and personal skills

$>$ Gain experience and to determine our career goals before graduation

Resort is defined as any place or places with pleasant environment and atmosphere conducive to comfort, healthful relaxation and rest, offering food, sleeping accommodation and recreational facilities to the public for a fee (definition per DOT Rules on Accreditation) 
A resort is a place used for relaxation or recreation, attracting visitors for vacations, tourism and/or going swimming in a pool and/or a nearby body of water. Resorts are places, towns or sometimes commercial establishment operated by a single company.

A resort is a full-service lodging facility that provides access to or offers a range of amenities and recreation facilities to emphasize a leisure experience. Resorts serve as the primary provider of the guests' experience, often provide services for business or meetings, and are characteristically located in vacation-oriented settings (University of Memphis, 6 October, 2009).

Gokarna Forest Resort is situated inside the Gokarna Protected Forest which in the past used to be the private royal hunting ground of the kings of Nepal. The quiet, natural and peaceful environment of the resort makes it the perfect getaway for relaxation and indulgence with the most exotic forest views from its cottage rooms.

The Gokarna Resort has its own historic character as well as values, suitable for both short and long stay, is fashioned as the fusion of modern design and the noblesse of original heritage interiors. This exceptional away from the city life is located away from both domestic and international airport. It continues to be the eco- friendly leading luxury resort for business and leisure. Gokarna forest resorts 100 rooms is a perfect venue for conferences and they offer team building packages and a wonderful wedding setup. The rooms have cozy atmosphere and are meticulously furnished with 100 deluxe rooms, club rooms and suite rooms with different sizes. This resort offers options for interconnected rooms for family and groups. Rooms are created, with an emphasis on the highest quality of materials, with smoke detectors, safe locks, working desks, LCD TV set with satellite reception, In-room tea/coffee making facility, direct call phone, high-speed Internet connection and a mini bar. Regardless of why guest have decided to visit, be it a short-term visit, long-term business trip, untraditional family holiday or comfortable honeymoon, or just looking for pleasant, quiet and luxury stay, Gokarna resort has created.

With the historic character of the resort and the new and upgraded facilities, the Gokarna resort will continue to be the Kathmandu's leading eco-friendly and leisure resort. Although it is an ultra modern resort, the traditional Nepali architectural features have been preserved. It captures the old charm and style of Kathmandu, while providing the international quality standards of accommodation and dining facilities. The embodiment of history, legend and tradition, the Gokarna resort is a perfect blend of contemporary international standards and time-honored tradition. Explore Nepal's rich cultural heritage while finding solace in the luxurious comfort of this former Rana Palaces.

Traditionally the private royal hunting grounds of the Kings of Nepal, this temperate forest of medieval Kathmandu valley is a conserved area, never denuded 
in over 500 years of preservation. A tranquil heaven existing in serene harmony with nature the forest provides shelter to a wide variety of birds and animals and the forest abounds with spotted deer and monkeys, which are not difficult to spot.

The guest visiting there can enjoy a game of golf or horse rides, spa treatments, forest walks, jungle paint ball games, bird watching, cycling, driving range practice or a cart tour. There is so much to enjoy, or guest can simply enjoy doing nothing at all while relaxing in the natural harmony of the place.

A winding road climbs leads through the towering trees up to the main complex, comprising a mix of subtly majestic Malla period architecture, Rana period lodges, and sanctuaries harmoniously blending with nature. Further, on exotic our Forest View cottage rooms are set besides a century old restored Hunter's lodge.

Harmony Spa, just a few steps away, combines therapeutic care within a natural environment impossible to recreate elsewhere. The Spa encompasses specialized massage rooms, a beauty treatment center, an indoor swimming pool, a gymnasium overlooking the forest, and luxurious changing rooms each with a Sauna, Steam room, and Jacuzzi.

The 6,755-yard par 72 golf course designed by Gleneagles Golf Developments of Scotland lies in the grassy valleys below. It is a delight for recreational golfers and one of the highlights of the professional tour in the region.

An organization requires a formal structure to carry out its mission and goals. An easiest way to represent that structure is by an organization chart. Figure 2.1 presented below provides with the organizational chart that shows the management positions in Gokarna Forest Resort. 


\section{Figure 1: Organizational chart of Gokarna Forest Resorts}

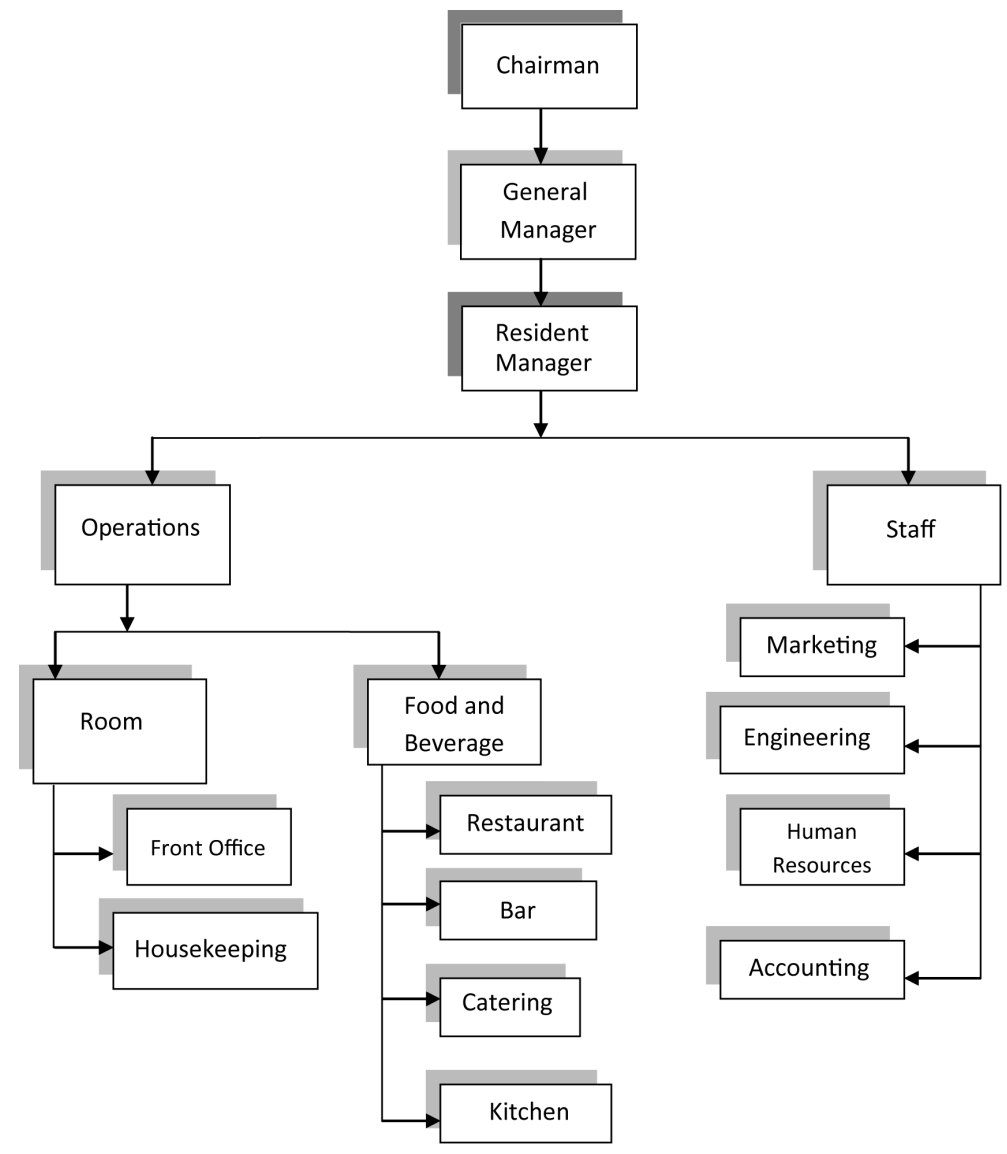

As presented in figure 1 above, Gokarna Forest Resort comprises of various functional departments categorized under functional and staff department. These entire departments are observed and regulated by the General Manager. Although there are separate manager for each specialized department the final decision making power is solely on General Manager. The present intern also works under the direct supervision of General Manager in both the department.

Typically, the Rooms Department includes Reservations, the Front Office, Housekeeping, and Telephone Operator. Responsibilities of the Rooms Department include reservations, guest reception, room assignment, tracking the status of rooms (available or occupied), prompt forwarding of mail and phone messages, security, housekeeping of guest rooms and public spaces such as lobbies, and answering 
guests' questions. To perform these many duties effectively, the Rooms Department may be divided into a number of specialized subunits. To complicate matters, in many instances these subunits are also referred to as departments. For example, the Laundry Department is responsible for cleaning and pressing the entire hotel's linens and employee uniforms as well as guest laundry.

\section{Front Office Department}

Front Office Department is the first department noticed by the guests whenever they enter into the hotel. It is the department responsible for the sales of the hotel rooms through systematic method of the reservation followed by the registration and assignment. Front Office Department deals with guest relations and processing of the various types of reservation as per guest requirement, by providing the right product at right price for right customer. Not only this, but it also deals with those services which are insensible dealing with guest comfort, satisfaction and value for money. So this department has the prime rule for image building of the resort. It is regarded, as the "Nerve Centre" of a resort as such is an excellent place to gain a detail understanding of how a modern resort establishment operates or functions.

This is the only department which got first and last point of contact of every guest with the resort. The front office is where guests are greeted when they arrive, where they are registered and assigned to a room, and where they check out. Usually, the telephone operator, other guest communications functions, and the bell staff or those employees responsible for delivering luggage and messages and attending to special guest requests fall under the front office umbrella. The Reservations Department takes and tracks the hotel's future bookings. The Housekeeping Department is responsible for cleaning guest rooms and public spaces.

A great deal of interdependence exists among the subunits of the Rooms Department. For example, reservations must inform the front office of the number of presold rooms each day to ensure that a current inventory of salable rooms is always available. On the other hand, the front office must let reservations know whenever walk-in guests (those who do not have reservations) register. A similar level of cooperation is required between the Front Office and Housekeeping. When a guest checks out, the Front Office Department must inform Housekeeping Department so that the room may be cleaned. Once a room is cleaned, Housekeeping Department must inform the Front Office Department so that the room may be sold. Certain tasks within the Rooms Department must occur in a specific order. For example, Housekeeping Department cannot properly provide a guest room if the laundry does not supply enough clean towels or bed sheets. Engineering cannot replace a defective light switch in a guest room if Housekeeping Department does not report the problem. Effective management of this busy department calls for 
standardized plans, procedures, schedules, and deadlines, as well as frequent direct communication between the executives who manage the key operating units of the Rooms Department.

\section{Food and Beverage Service Department}

The primary function of the Food and Beverage Service Department is to provide food and drink to a hotel's guests. The Gokarna Forest Resort have a coffee shop, a multi-cuisine Durbar Restaurant, 8848 meter bar, Clubhouse Restaurant serving Thai and Chinese cuisines, room service, four banquet halls, and two function rooms where food and beverages are served. On a busy day (or night), it is quite likely that functions will be booked in many outlets at the same time. In addition, some outlets have multiple events scheduled for a single day. As you can see, there is great diversity in the types of activities performed by a Food and Beverage Service Department, requiring a significant variety of skills on the part of its workers.

Because of the diversity of services provided, the Food and Beverage Service Department is typically split into subunits. The executive chef, a person of considerable importance and authority in Gokarna Forest Resort, runs the Food Production, or Kitchen Department. A variety of culinary specialists responsible for different aspects of food preparation report to the executive chef. The actual serving of food in GFR is usually the responsibility of a separate department, headed by the Food and Beverage Director. The Food and Beverage Service Department is composed of the individual restaurant and outlet managers, captain, waiters, waitresses, intern and casuals. There is bar manager, executive barman, bartender who looks after the beverage revenue of GFR.

For cleaning the Food and Beverage outlets as well as of washing pots and pans, dishes, glasses, and utensils there is another subunit known as the Stewarding Department. It is only through continuous cooperation and coordination that a hotel's food service function can be carried out effectively. A guest who is dining in a hotel restaurant, a banquet functions, events etc requires the joint efforts of the Kitchen, Food and Beverage Service, and Stewarding departments. The sequence of events and cooperation required among the Food and Beverage Service staff is even more important than in the Rooms Department, thus increasing the importance of communication between managers and employees alike.

As baby boomers requiring, "every skilled worker of every age to be needed"(Tulgan, 2004; in Chi, Maier \& Gursoy, 2013). By 2013, employees aged 3545 will be in the prime of their career contribution to the workplace. The majority of mid level managers will be hired from this group and it is expected that there will be a $10 \%$ decrease in the number of available employees to fill these leadership positions (Tulgan, 2004; in Chi et al., 2013). As a result, workers, significantly younger while the majority of upper level managerial positions with workers who are significantly 
younger while the majority of upper level managerial positions are still being held by Baby boomers, and partly by Generation X'ers. In fact, in today's hospitality workplace, multigenerational management terms are trying to lead multigenerational workers (Ross and Boles, 1994; in Chi et al., 2013).

For purpose of this study and the generational context within the workplace, literature suggests that three generations are represented in today's workplace: Baby boomers (born 1946-1964), Generation X (born 1965-1980), and Millennials (19812000) (Glass, 2007; in Chi et al., 2013).

\section{Baby Boomers Generation (born 1946-1964)}

These individuals were raised in an era of extreme optimism, opportunity, and progress. Boomers, for the most part, grew up in two parent households with the mother as primary caregiver and the father as sole income earner. They lived in neighborhoods and attended schools that were relatively free from crime and violence. They represent about two thirds of all U.S. workers. On the job, they value loyalty, respect the organizational hierarchy, and generally wait their turn for advancement. Many baby boomers reflecting back on their lives, realize they have focused the majority of their time on their job and want to find a grater balance between work and leisure. Boomers often feel younger workers needs to carry the loads and put in their time.

\section{Generation X (born 1965-1980)}

They grew up in two-career families in a society with rising divorce rates, and economy in recession, increased crime and violence in schools, cooperate downsizing and loss of job security (Dennis, 2009; Lancester \& Stillman, 2002; in Chi et al., 2013). On the job, they tend to be skeptical of the system, noticeably independent, like to be in control, view job freedom as reward, seek training opportunities that enhance their skills and want fast feedback.

\section{Millennials (1981-2000)}

The children of Baby boomers or early Gen-Xer parents, Millennial were born into the current high-tech, neo-optimistic times. Although millenials are the youngest workers, they are fast learners, impatient, the most technologically savvy and when they question authority, it is usually for the right reasons (Zemk et al., 2000; in Chi, Maier \& Gursoy, 2013). Millennial want their supervisors and other co-workers to provide direction with clear descriptions of the task or project to be completed (Gursory et al., 2013;in Chi et al., 2013). Brainstorming is often difficult for millennial and they respond better to specific benchmarks as guides. (Solnet \& hood 2008; in Chi et al., 2013) reported specific work values associated with millennial included: (1) respect, (2) recognition, (3) input, (4) involvement, (5) 
continuous development, (6) supportive management, (7)fairness and (8) concern for individuals. Millennial' view of the world has been shaped by MTV. AIDS, terrorism, globalization, the end of the cold war, weapons of mass destruction, high public distrust of government, and influential special interest groups. This influence is reflected in beliefs help by many millennial who: (1) are committed to making a life, not just a living; (2) view team-building, engagement, and partnerships as essential to leadership;(3) recognize that which diversity come new prospective, ideas and insights (Chi et al., 2013).

In their study, Chen \& Choi (2008) and Chi et al. (2013) identified a hierarchy of work values among hospitality managers across three generations (Baby boomers, GenX and Millennials). They revealed four dimensions of managerial work values that significantly impacted employee recruitment and retention across the three generational groupings: 1) comfort and security, 2) professional growth, 3) personal growth and 4) work environment (Chen \& Choi 2008; in Chi et al.,2013).

Research pertaining to younger managers in the hospitality industry (Millenials) indicated they value, more than both GenX and Baby boomers, the development of good work habits and involvement in group constructed activities and preofessional organizations that generate competency and skills training (Ryan et al.,2009; in Chi et al., 2013). Specifically younger managers tends to value leadership competencies surrounding motivational skills, team building, flexibility and ethics more so than older managers (Ryan et al.,2009; in Chi et al.,2013). Furunes and Mykletun (2008; in Chi et al., 2013) found hospitality workers views of younger managers primarily center on empathy formal knowledge and communication skills.

The intern during the internship found that the majority of the workers belong to the Millennial with few Gen X people. These two categories of people dominate the composition of the hospitality industry workforce. Most of the young people can be found out in every department with few young minds being able to be at managerial position. And the rest are the people with years and years of work experience but lack of educational degree and sometime this can lead to the workplace dissatisfaction and violence. The case when an entrant tries to tell the people already spending decade doing that work can be very awkward for the latter resulting in workplace violence. On the other hand, the baby boomers are the people who are now enjoying their life after the hardships in their life and most of the time is guests who pass their responsibilities to their young ones and go out for vacation.

Employees are quite often required to have specific skills and abilities. Spivack (1997; in Kim, 2008:20) stated that there is 'skill development issues' related to changes occurring within the tourism and hospitality industry. Christou (1999; in Kim 2008:20) highlighted that skills should be given priority when recruiting new 
staff. Many authors (Damitio, 1988; Damitio \& Schmidgall, 1993; Hsu \& Gregory, 1995; Knutson \& Patton, 1992; Ladkin, 1999; Ley, 1980; Riley \& Turam, 1989; in Kim, 2008:20) pointed out that specific skills would be very important for developing a career because hospitality is becoming more globalised. The need for multicultural abilities and skills is more critical for employees working in the industry (Sigala, 2001; in Kim 2008:20).

Baum (1990), Finegold, Wagner, and Mason (2000) and Jauhari (2006; in Kim, 2008:21) stressed that hotel managers should have multiple technical skills. For example, a F\&B manager has to make a decision buying stocks, storing, costing, and processing, to serving food to customers (Riley, 2005; in Kim, 2008:21). Using multiple technical skills allows an F\&B manager to control and manage their department, and this requirement remains the same in all situations, regardless of size or quality, be it a grand hotel or formal restaurant. A F\&B Manager needs multiple skills in areas including accounting, human relations, marketing, customer service and communication in order to effectively manage a department (Riley, 2005; in Kim, 2008:21). These skills are required by all department managers if they are to work more effectively and efficiently. Hence, technically multi-skilled staff will ultimately offer greater value to the company.

Jauhari (2006; in Kim, 2008:21) also stated that multi-skilling allows a person to manage a large number of tasks at the same time. Multi-skilling may affect how employees approach a wider arrangement of employment opportunities. Furthermore, multi-skilling can increase an employee's understanding of the wider processes involved in different kinds of functional activity (Finegold, Wagner, \& Mason, 2000; in Kim, 2008:21). Baum (1990; in Kim, 2008:21) stated, hospitality graduates needs to have multiple skills to handle the rapidly changing working environment of the hospitality industry. Multi-skilled employees will be more enterprising and adaptable.

Ladkin and Juwaheer (2000; in Kim 2008:21) argued that effective communication skills are fundamental for career development in the hospitality industry. Communication skills are argued to be a significant skill by many (e.g. Ruddy, 1990; Achorn, 1992; Knutson \& Patton, 1992; Stutts, 1995; in Kim, 2008:21). For example, Achorn (1992; in Kim, 2008:21) noted that in order to succeed, GMs in the Sheraton hotel group needed a good education and good communication skills. Knutson and Patton (1992; in Kim, 2008:21) found that hospitality students believed that effective communication skills were especially important for GMs. However, other skills are also stressed, for example, managerial accounting skills (Damitio, 1988; Damitio \& Schmidgall, 1991; in Kim, 2008:21), and technical, leadership and interpersonal skills (Kay \& Russette, 2000; in Kim, 2008:21). 
It appears that multi-technical skills, good communication skills, leadership skills and financial skills are necessary to operate effectively in the hospitality industry. Knowing the skills required by the hospitality industry is vitally important to hospitality students.

The internship of the intern was based on the two departments: Food and Beverage Service and Front Office Department. The intern was assigned with following tasks related to Front Office Department while working as an Intern:

$>$ Perform the regular room reservation and cancellation tasks.

> Handle business correspondence related to room reservation and cancellation.

$>$ Receive telephone calls within the three rings.

$>$ If telephone is from outside, first greet the guest as per the time, second identify your organization, third identify yourself and assist the caller.

$>$ If the telephone call is internal, greet the caller as per the time, identify yourself and assist the caller.

$>$ Check the register for Wake- up call and follow up at the written time.

The intern was assigned with following tasks related to Food and beverage service Department while working as an Intern:

$>$ Welcoming guests

$>$ Demonstrating menu knowledge-Answering questions

$>$ Up selling specialty items

$>$ Describing dishes-Taking orders (beverage and food)

$>$ Handling complaints

$>$ Bring out food

$>$ Clearing empty plates

$>$ Refilling drinks

$>$ Bringing extra items requested by guests (sauce, extra condiments etc)

$>$ Ensuring the food came out as desired

$>$ Clearing all plates at end of meal

$>$ Crumbing the table

$>$ Offering after dinner drinks and dessert

$>$ Cash handling (when processing the check)

$>$ Thanking the guest for coming in and assisting in any other ways

$>$ Wiping down your tables 
> Refilling salt, pepper, sugar, olive oil etc.

$>$ Emptying and cleaning coffee station

$>$ Emptying and cleaning up coffee machine and bar area

$>$ Stocking plates, silverware, to-go boxes, bottled water etc

$>$ Placing items in back fridge

$>$ Wiping down shelves and server station

$>$ Wiping down menus

$>$ Ensuring guest satisfaction

Guest satisfaction is the first and foremost motive of the hospitality institution and they try their best to make a pleasant experience of the guest. During the course of offering services they have to face various types of guests.

Understanding of customers as well as customer behavior is the most crucial factor in the hospitality industry. Hospitality experience is different from client to client for instance leisure guest behavior is distinct from business client. During internship the intern have to face the deviant customer behavior like:

Vandals (who intentionally deface organizational property)

Thieves (referring to customers who have no intention of paying for a service)

Belligerents (represents customers who act in an argumentative or aggressive fashion toward service personnel)

Family feuders (who quarrel with other customers and family members)

Deadbeats (denotes customers who fail to pay for services that they have already received)

Rule breakers (customers who fail to confirm to the unwritten rules and norms of service encounters) (Lovelock, 1994; in Boo, Mattila \& Tan, 2013:181). Beside, some other types of customer behavior to be faced in hotel industry are as follows:

Undesirable customers

Property abusers

Service workers

Vindictive customers

Oral abusers

Physical abusers

Sexual predators (Harris and Reynolds, 2004; in Boo et al., 2013:181) 
Personnel working in the hotel or resort need to be ready to face unpredicted guest also. So intern should make up their mind to face every challenge tactfully that may be from customers' side or from senior employees. Deviant behavior can be shown from employees' side also to the intern like not cooperating, doing vulgar and physical abuse, discriminating in facilities provided etc.

The dissatisfaction in customer service mayleads to loss in business. So, very critical situations need to be handled carefully. Although misbehave is done by customers we cannot say this is your fault to the customer directly. Because in hospitality sector guest is always right. So, intern need to consult with the supervisor before taking any action. In most of the cases focal customers are suffered from deviant customers. In such cases the service providers need to be careful about focal customers' satisfaction that may be done by relocating the table, compensating, apologizing, separating the focal customers from the deviant customers and correcting the deviant behavior exhibited by fellow customers.

In the process of advancement as a career in the field of hotel industry, one should be well equipped with basic as well as advance knowledge about a hotel, its operation and how it works. A project exposure of this scale of works really provides an opportunity to the students to be aware of day to day operation of the hotel as a whole. This period also provides knowledge about hospitality industry that one should carry to build up his/her career as an hotelier.

This is the time to advance and to introduce the present intern to new people and give opportunity to tie-up relationship with successful hoteliers. The industrial training builds confidence in an individual and helps overcome all the difficulties in the field of the hotel. The present intern got the chance to learn about the various challenges to be faced in day to day activities and sometime unwelcomed natural challenges like earthquake. So the present intern could learn to handle such crisis of low occupancy, no business and massive destruction.

The Internship program provides an opportunity to face the real hospitality environment for which we are getting prepared. It was really helpful implement the theoretical knowledge that was learnt during the college period. In fact, the overall exposure served as training and boosted the confidence of the present intern.

The intern firmly believes that six month experience at Gokarna Forest Resort has helped the present intern to develop her professional skills. The present intern learned how the hospitality company like Gokarna Forest Resort develop its various strategies to compete with its competitors, how it employs new people to develop new products, how it differentiate its products from that of its competitors. Also, the present intern earned how to approach prospective clients, negotiate with them and even maintain future relations with them. Hence the experience that present 
intern gained during her internship was the most important gain from the program. Beside this the present intern develops her communication skill by talking with foreign guest, her self confidence level is developed, she can now handle service task easily.

One of the positive outcomes of the internship is the ability to understand and implementation the concept of the cross cultural competence. Cultural competence refers to "an ability to interact effectively with people of different cultures" (Wikipedia, 2014; in Editorial, International Journal of Hospitality Management, 2014:37), Cultural competence enables people to be aware of their own culture, recognize the differences between their own culture and other cultures, understand how people from other cultures think, do business see others and why they act the way they do. (Editorial, International Journal of Hospitality Management, 2014: 37)

In hospitality establishments' people from various backgrounds like ethnic groups, caste, culture work together. Employees also come from different cultural background so the way they think and behave is different from another colleague. Beside employees customers who visit the property are from various countries, culture. So, there is huge difference in the way they think, act and react. Like the gestures and expression of Chinese, Japanese guest is distinct from American customer. Therefore, worker need to be able to communicate effectively with customers and colleagues from unique cultural backgrounds and behave competently to better suit challenging cross cultural situations. Miscommunication due to cultural difference may lead to guest dissatisfaction; therefore such cases need to be handled tactfully.

Cross cultural competence refers to the knowledge, skills and affect/motivation that enable individuals to adapt effectively in cross cultural environment. Cross cultural competence is defined here as an individual capability that contributes to intercultural effectiveness regardless of the particular intersection of cultures. Although some aspects of cognition, behavior or affect may be particularly relevant in a specify country or region, evidence suggest that a core set of competencies enables adaptation to any culture (Hammer, 1987; in Wikipedia, 2015).

When a student enters professional world leaving its college environment then they get to feel the real working environment. Though they may have been subjected to good quality practical classes during their course of study it is not enough for them to work in the real environment. For a person of hospitality and tourism industry it is very essential to know that the theoretical environment is very different with the real life-working environment.

In hospitality operations, knowledge can be defined as "that knowledge which is related to company's customers, products and services, operational procedures, 
competitors and job associates"(Yang \& Wan, 2004; in Kim \& Lee 2013:324). That is, services in the hospitality industry have complex work processes and guest interfaces that can be differentiated into four categories of knowledge: task-specific knowledge, task related knowledge, transactive memory, and guest-related knowledge (Bouncken, 2002; in Kim \& Lee, 2013:324).

In the twenty-first century, one of the critical factors for sustainable competitive advantage is how to leverage knowledge resources to develop strategic plans for business. Organizations must therefore manage or retain critical knowledge in effective ways (Bock \& Kim, 2002; in Lee \& Kim, 2013:324)

In today's highly competitive market environment, a hotel's ability to innovate is essential to achieving sustainable competitive advantage (Tajeddini, 2010 in Lee \& Kim, 2013:324). Intense competition, rapid technological evolution and globalization, and rising expectation from savvy consumers have created unprecedented challenges for the hotel industry, and hotel's ability to enhance service innovation is of interest to both scholars and practitioners. In particular, as superior service quality is a major factor in customer satisfaction and loyalty. Hotel can work on their employees service innovative behaviors by enhancing employee knowledge sharing of consumers sophisticated demand and preferences and tailoring their service accordingly (Hallin \& Marnburg, 2008; in Lee \& Kim, 2013:324).

Knowledge-sharing activities are therefore crucial for hotels' competitive advantage and enhance the ability to meet customers' diverse and rapidly changing demands. Specifically, this knowledge-sharing behavior is important in the hospitality industry due to the immense costs of knowledge loss caused by high rates of employee turnover (Kim \& Lee, 2010, 2012; Yang \& Wan, 2004; in Lee \& Kim, 2013:325). However, employees often refuse to share knowledge because they worry that doing so may reduce their opportunities for promotion or because doing so requires uncompensated time and energy (Bock et al., 2005; in Lee \& Kim, 2013:325)

The second issue in the research pertains to the two distinctive types of individual knowledge-sharing behaviors: knowledge collecting and knowledge donating. Knowledge sharing includes employees' willingness to communicate with colleagues (i.e., donate knowledge) and to consult with colleagues to learn from them (i.e., collect knowledge) in the development of new capabilities. However, with only a few exceptions (Tohidinia \& Mosakhani, 2010; Van den Hooff \& De Ridder, 2004; Van den Hooff \& Hendrix, 2004; in Lee \& Kim, 2013:325), most studies have used knowledge sharing-behavior as a unidimensional construct. Most studies, therefore, do not fully explain the relationship between determinations of knowledge-sharing behavior, knowledge-sharing behavior itself, and its consequences. 
Button et al. (1996; in Lee \& Kim, 2013:326) suggested that learning goal orientation and performance goal orientation are two distinguishable dimensions of goal orientation, which itself has both situational and dispositional aspects in achievement situations.

Knowledge Management (KM) refers to the creation of knowledge repositories, the improvement of knowledge acquisition; the enhancement of the knowledge environment; and the management of knowledge as an asset (Rowley, 1999; in Mistilis, 2005:5). It enables groups to share and re-use information resources, and have the power to make decisions faster and less expensively.

From the literature (Nonaka \& Takeuchi, 1995; Rowley, 2000; in Lee \& Kim, 2013:326-327), knowledge management can be operationally described as the process of (1) knowledge acquisition (i.e., collecting and identifying useful information), (2) organizing knowledge (i.e.,enabling employees to retrieve organizational knowledge), (3) knowledge leverage (i.e., exploting and usefully applying knowledge), (4) knowledge sharing (i.e., disseminating knowledge through the whole organization), and (5) organizational memory, i.e., storing the knowledge in the repository. In particular, knowledge sharing is a prerequisite for innovation (Kim \& Lee, 2010, 2012; in Lee \& Kim, 2013:327), organizational learning (Senge, 2006; in Lee \& Kim, 2013:327), and the development of capabilities and best practices (Kim \& Lee, 2010; in Lee \& Kim, 2013:327), and thus it is central to managing knowledge.

Knowledge sharing refers to the provision of task information and know-how to help others and to collaborate with others to solve problems, develop new ideas, or implement policies or procedures (Cummings, 2004; in Lee \& Kim, 2013:327). Knowledge sharing also can be defined as "a social interaction culture, involving the exchange of employee knowledge, experiences, and skills through the whole department or organization" (Lin, 2007: 315; in Lee \& Kim, 2013:327). Knowledge sharing occurs when an individual is willing both to learn (i.e., knowledge collecting) and assist (i.e., knowledge donating) others in developing new capabilities (Block \& Kim, 2002; in Lee \& Kim, 2013:327). Knowledge sharing is thus "the process where individuals mutually exchange their knowledge and jointly create new knowledge" (Van den Hooff \& De Ridder, 2004: 118; in Lee \& Kim, 2013:327).

The intern before commencing the internship has a very little on field knowledge but had adequate theoretical information. When the intern was subjected to the real working environment, couple of days was spent feeling awkward. Then, slowly and gradually, the intern started to learn about tasks and their procedures and this is where the knowledge sharing is carried out. The two dimensions of knowledge sharing- knowledge collecting and donating was thoroughly adopted by the intern during whole internship. Collecting knowledge means to have interaction with the 
co-workers and the senior staff regarding the various aspects of the tasks like what, how, why, where, etc. The intern being curious and the zeal to learn resulted to the constant productive interactions with the colleagues. In this way, the knowledge was acquired. To complete the knowledge sharing behavior, the gained knowledge should be disseminated among others and they should also know the basics of the place. During the internship the intern donated the knowledge while interacting with colleagues and if someone was not sure anything regarding the establishment and the service, the intern explained very nicely and the clear communication made the knowledge transfer very effective.

The intern was lucky to have a constant interaction with the upper level staffs which could provide lots of valuable information and knowledge regarding the service and ways to be successful in the field.

Broadly, educational theories can be classified according to two domains: the theories of learning and the theories of knowledge they profess (Hein, 2006:345). All educational theories include views on both these topics and their combination suggests particular educational practices (pedagogy) and results in different kinds of educational programs.

Theories of learning can be roughly grouped along a continuum from "passive" to "active", that is, from theories, on one extreme, that consider the mind to be a passive recipient of new sensations that are absorbed, classified, and learned, to the opposite extreme that postulates that learning consists of active engagement of mind with the external world, wherein the learner gains knowledge by thinking about and acting on the external world in response to stimuli. (Bransford et al., 1999; in Hein, 2006:345). Theories of knowledge are concerned with whether learning entails acquiring truths about nature or constructing knowledge, either personally or culturally, that is "true" only for those who accept it.

Stimulus-response theory (behaviorism) persists dominantly in the formal sector; it provides the theoretical basis for the belief that progress in schools can be adequately assessed through short-answer, paper-and-pencil tests (or, more commonly today, fill-in-the-blank computer-scored tests); that both knowledge and learning settings can be isolated from real-world contexts without diminishing learning; as well as a number of other regimented practices common to state school systems. (Hein, 2006: 345) 
Fig. 2. Theories of education

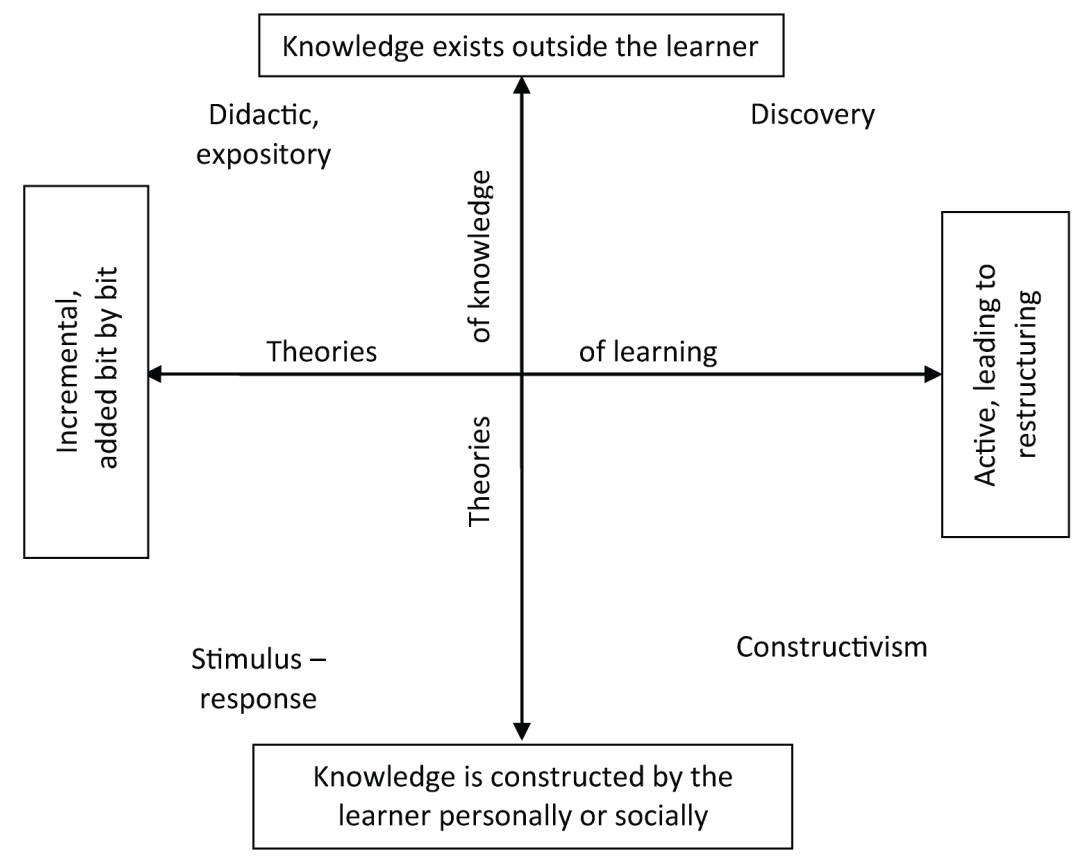

Source: Hein (2006:346)

Knowledge sharing or flow of correct information and knowledge can be a useful tool at present to customize the service and gain an edge over its competitors. Various people have various ideas and the things running through their mind and the pool of people can give you the best of idea to outplay the competitors. So, a session of haring or communicating the ideas can be beneficial in the long run. The intern was provided with ample opportunities to put the views or any other idea so that the current level of service can be upgraded into something new and unique which can be used to gain a competitors advantage. So, the interns who may feel something in their mind should put their thing to colleagues and seniors and it can be very positive regarding the career.

During the learning phase in college, theoretically almost all subjects were covered by the instructors. For instance, while studying about the restaurant, it was taught the entire processes from guest arrival to their departure. Though it was based on the theory the problem starts when practical work was started in a restaurant of the above mentioned resort with guests and all. The problem is same with all the departments and every intern because the real life working environment cannot be depicted and the working under replica is never going to be same as working in real 
scenario. So the actual difference between the theoretical study and internship is the lack of exposure to the real case scenario and the lack of ability to make an adjustment between the theoretical learning and working environment.

During the course of study almost all of the theoretical aspects are given to the students but still they cannot show it effectively during the intern. The reason for this is the inability of the teaching institutions to cast an image of the working environment and the reluctant nature of the students. They tend to think the internship will go along without any problem and are not eager to learn about the working environment more briefly prior to their internship training.

Hands-on experience cannot be imparted through lectures. It can only be gained through direct activity, either laboratory or real world confrontation. Laboratory learning is clinical, whereas, real-world confrontation, known as industrial training or internship, affords students a first hand glimpse of reality. There is no substitution for the "sting of battle"(Collins, 2002:93).

As an intern, though space to work was limited, still it was manageable to grab abundant experiences. The best of every opportunity given was made the utmost use of, the intern's abilities and knowledge to fulfill all required responsibilities. The present intern could implement the academic skills into practice and efforts were highly acknowledged. There is however some gap between theoretical knowledge and real life practice, yet the managerial level staff members is quite open towards upgrading current approach, which was extremely motivating.

This exposure played a vital role in the overall development of the interns personal and professional grooming along with the improvements in various skills i.e. technical, communications. Though man is born alone to complete a task effectively and efficiently teamwork is mandatory. Attitude, smile and eagerness to serve are the three most valuable assets one need to posses to work in hotel industry are the lesson learnt through this internship project exposure.

Eventually, this internship experience was a milestone to the academic and professional experience. The present intern thoroughly enjoyed the challenges that came along every single day and admire these lessons that has been learnt will be a valuable one for my future endeavors as well.

The theoretical knowledge that student learn in the class room is complemented by the practical learning in the real work environment. So, the internship is the opportunity to make your learning complete and effective with real work exposure.

Knowledge systems are often created to facilitate the circulation of best practices (Bansler \& Hagn, 2003; in Mistilis \& Sheldon, 2005:5) and may be called knowledge sharing systems. They provide an integrated approach to identifying, managing, 
sharing and reusing all of an enterprise's information assets with advance technology (Zhang et al., 2002; in Mistilis \& Sheldon, 2005:5). Others have noted the importance of the knowledge flow (Kakabadse et al, 2003; in Mistilis \& Sheldon, 2005:5) from data to information to realization to action and reflection and finally to wisdom. More specifically, KM systems within an organizations are archives of information on employees, customers, processes, products and decisions-which create an audit trail and also a sense of security and provides some understanding of cause and effect (Fowler \& Pryke, 2003; in Mistilis \& Sheldon, 2005:5)

The internship has enhanced the professional skills and capacities of the intern. The intern with the involvement in the day to day operations of the service and housekeeping department has acquired the knowledge which can be applied when the intern starts his professional career. From the basics of welcoming the guest and taking care of the entire dining at the restaurant to clearing the bills and settling the account through IDS(software) was learnt and the knowledge of preparing the room and various use of chemicals and standard procedures of making a bed was learnt which were the main things learnt during internship in a nutshell.

But, the internship has the extensive effect on the personality and confidence of the intern. The intern now has the experience and has boosted the confidence to work on any property throughout the world. During the internship, the intern had to face various situations like the peak season with high occupancy and demanding guests from across the globe and being successful in catering them has resulted to the enhancement of confidence.

The intern has enhanced the communication skills, interpersonal skills, time management skills and stress management skills with the involvement in the real work environment in the internship. In the field of hospitality industry, time management is very crucial. Various projects are run simultaneously in various departments. So to ensure proper coordination among departments time management skill is crucial. Having worked in the marketing department, communication as well as professional skills are very important while dealing with existing as well as prospective clients.

Thus, internship provided the chance to experience the real working environment inside an organization. It exposed me to various situations where various skills were needed. Regular presentations helped me to develop our communications skills which will be beneficial in the future as well. Professional skills, on the other hand will help me to adapt in a formal organization bridging the gap between our student life and professional life.

The internship has taught a few lessons to the intern which are given below

$>$ Never be on time. Always arrive early. Be at least 15 minutes early every day. That way, if you are running late, you will be on time. 
$>$ Ask your supervisor what the expectations for productivity are. This will immediately make you stand out from $95 \%$ of the other employees.

$>$ Be part of the solutions. Quit whining about what's wrong and start being vocal about what's right! A positive attitude goes a long way with many supervisors.

$>$ Be quiet and work. Quit gossiping and get to work. Your employer is not paying you to gossip. When one of you is talking a lot, two of you are not working a lot.

$>$ Always be productive. Don't let paper sit on your desk for days on end. Get the work done and move on to the next thing as quickly as possible.

$>$ Hold your head high and be confident. A calm, assured energy will take you much farther than carrying yourself in a hunched up ball.

$>$ Don't spend a lot of time on personal phone calls.

Students generally complain about the quality of the internship programs in mainland China. For some tourism and hospitality schools, they don't arrange the internship placements for students; instead, students find jobs by themselves. What's more, on-site visits of school mentors as well as communication between students and school mentors during the internship are rare. Moreover, most internship representatives are academic staff members who are looking after not only the coordination and arrangements of internship program for their students, but also teaching and research. Workloads of these staff members can be very heavy which leads to a downgrade of effectiveness and efficiency of the coordination function of their internship programs. In addition, the job nature of internship positions in mainland China usually involves long working hours with high visibility, such as waiters, waitress, chambermaids, front desk personnel, etc. and internship positions are usually considered as "set posts" without any job rotations which may decrease the interest of hospitality students toward internship (Hou, 2004; in Yafang \& Gongyong n.d. :1070). Benefits for interns are rare while the employment conditions are poor, such as low rate, heavy workloads and no pay for overtime duties.

Some employers even don't pay attention to the objectives of the internship, and they just treat interns as a supplement for a labor shortage instead of developing potential employees through internship. So students generally complain about the quality of the internships which result in increasingly high fallout rates of graduates from the tourism and hospitality industry (Lam \& Ching, 2007; in Yafang \& Gongyong n.d.:1070)

For the future prospects of the hospitality and tourism industry, that they should be clear about many things. The people who are already a part of it or undergoing 
their study they must have some ideas until now and they should try to groom them accordingly.

For those who are eager to enter the world of hospitality and tourism industry you are cordially welcome. It is a glamorous industry, which will provide you with lots of opportunities. However, you must be sure about your dedication and hard work and most of all discipline. You must pace yourself within a certain limit and criteria while presenting to guest and whatever your problem and attitude are should replace them with decent characteristics and etiquettes. One of the concepts called Emotional labor is very necessary to understand considering the requirement of hospitality and tourism industry.

Hospitality and tourism employees particularly face demands for emotional labor, as there occupations require them to express feelings such as enthusiasm friendliness and cheerfulness dispute negative emotions that they may experience (Pizam, 2004; Wang, 2009; in Shani, Uriely, Reichel \& Ginsburg, 2014:150).

The term emotional labor was first introduced by Hochschild (1983:7; in Shani et al., 2014:151) who defined it as "the management of feelings to create a publicly observable facial and bodily display" which is "Sold for wage and therefore has exchange value."

Interns need to make their facial expression and interaction as per customer desire although they are not satisfied with the organization. They may not be motivated to work in some instance due to unpaid work, during that situation also they to display desirable feelings and suppress undesirable ones.

In a situation where there authentic or experienced feelings are in conflict with those they are expected to express, service employees often cope with this 'emotional dissonance' situation through the use of 'surface acting' or 'deep acting' (Hochschild, 1983; in Shani et al., 2014). Surface acting involves modifying the feelings from the 'outside in'(e.g., the employees puts a sympathetic face when in fact is feelings irritable, whereas deep acting involves changing the feelings from the 'inside out' (e.g. the employee tries to feel empathetic and concerned to the customers difficult situations by imagining him /herself in the customer position) (Grandey, 2000; Kim, 2008: Rafaely \& Sutton, 1987; in Shani et al., 2014:151).

Internships and hospitality and tourism industry are compliment to each other. The role of internship is very crucial considering its effects to the new prospects of the industry. Internship provides an ample opportunity to learn about the real working environment and make up the mind of the potential professionals of the industry. To make the internship more effective the college and the industry should work very cordially and closely. The students should be given the department of their preferences as far as possible and the intern should not be treated as a working machine and made 
to work works beyond their capacity. Everyone expect something in return when they put lot of effort in doing their task. During internship every intern tries to do their best, they work in the same level of others employees but at the end of the day their work is not recognized by the supervisor. If there is a small mistake in their work manager is in front of him/her for bad word but there is not any acknowledgement and positive feedback for the good work they have been done. So, interns feel demotivated towards their work because they do not know what they have work for the payment, no appraisal just bad words, physical work and pain for good marks.

As far as the educational institutions are concerned their course design and lectures delivery should be crafted in a very practical way which can cover the real working environment and the practical should be conducted reflecting the real case scenario which can be done by collaborating with other colleges and making them working together and bring some guests to the practical and sending the students for industry part times more often.

Students also should be prepared about the initial hardships they face in the industry and be ready to work under pressure. They should acquire all the knowledge about the place they will be a part of in the future and students should be very active to dig out information about the new trend and practices going on their industry and their causes and what's the future are going to be like.

Internship is a learning period where you can have lots of knowledge and practical exposure which will be very beneficial when you start your way in the industry as professionals.

\section{Conclusion}

The literature relating to different career expectations, assumptions and ideas on work requirements between undergraduate hospitality management students and management employees in the hospitality industry shows that many gaps exist. Furthermore, a number of studies identified that hospitality management degrees are not important in the hospitality industry and industry work experience is more important than a hospitality management degree (Harkison, 2004a; Steele, 2003; in Kim, 2008:93). The hospitality employers and hospitality educators in these studies appeared to have different perceptions (Collins, 2002; Harkison, 2004b; Li \& Kivela, 1989; Raybould \& Wilkins, 2005; in Kim, 2008:93). Hospitality educators focus on teaching students as if they will be entering the hospitality industry at management level (Brien, 2004; in Kim, 2008:93).

Overall, students' satisfaction mean scores on their internship were low, which indicates that overall, students were dissatisfied with their internship experience, especially on the following items: 'coordination between schools and employers', 'opportunities for self-development', 'pay and welfare', 'work pressure', 'opportunity 
for work rotation', interesting and challenging work', and 'autonomy involved in the work' (Yangfang \& Gongyong, n.d.:1074).

The internships program's results have not seen much change in recent years. The conditions of students undergoing the internship experience and decided not to enter the industry are still in high volume in many countries, which emphasizing hospitality and tourism education as part of their nation's economic resources. The conditions of the university policy in relation to hospitality program development which includes internships has not seen any significant changes that could lead to increase the number of graduates going into the industry after essentially going through the internship experience and graduation. Rather, the internship experiences nowadays are seen "only" as a requirement to complete their university study. Still others see internship as an opportunity to network, to learn new fields or gain work experience (Seymore, Matthew \& Higham, 1997; in Abdullah, Zahari, Mat, Zain, \& Derani, 2015:36). However, the state of the matter is in relation to internships, it should be viewed as part of some hospitality academic programs rather than an optional element in any academic programs.

A practical implication as suggested by Koc, Yumusak, Ulukoy, Kilic \& Toptas (2014; as cited in Abdullah et al., 2015:36) is that in developing any internship programs and in order for it to be successful, a higher level of cooperation among universities and hospitality establishments is a must. Efficient and effective feedback systems should be established within the internship programs so that corrections and improvements could be made. Academics and managers on hospitality programs should not be complacent for finding sufficient positions for their students to have their internship experiences and let their students be exploited by businesses. Policy makers in the government (e.g. Ministries of hospitality, education and employment) should participate in the design and implementation of internship programs, so that internship programs reach their real and intended objectives.

To conclude, hospitality industry and its vigorous growth has made the internship more important and mandatory and the internship should be managed properly by the various players associated with it to have the maximum benefit to the interns as well as the industry. This paper portrays the internship in the view of an intern and provides various aspects of it. The internship is characterized by understanding and changes prior to stating, during internship and post internship. The level and theoretical attainment of education and the expectation prior going to the intern and the experience gained during internship along with understanding the concepts like emotional labor and cultural competence is connected to the post-intern change in an individual who has a very good understanding of the working procedures in the real environment. This paper will be proven very beneficial for the potential interns and all associated with this industry who wants to make them as part of this glamorous industry. 


\section{Acknowledgement}

We would like to thank Mr Dorjee Sherpa (GM of Gokarna Forest Resort), Mr. Rup Kumar Moktan (Restaurant Manager of Gokarna Forest Resort), Mr. Sujan Aryal (Principal of Nepal College of Management), Dr. C.P. Rijal, Mr. Anup Karki (Senior Program Coordinator of Nepal College of Management) for their support for my internship placement and report preparation.

\section{References}

Abdullah, R., Zahari, H., Mat, N.A.N., Zain, R.A, \& Derani, N. (2015). Hospitality Internships: An Employment Advantage or Perilous Experience. Journal of Basic and Applied Science Research, 5(8):34-38.

Boo, C.H., Mattila, S.A. \& Tan, Y.C. (2013). Effectiveness of recovery actions on deviant customer behavior-The moderating role of gender. International Journal of Hospitality Management, 35:180-192.

Brown, A.E., Arendt, W.S. \& Bosselman, H.R. (2014). Hospitality management graduates' perceptions of career factor importance and career factor experience. International Journal of Hospitality Management, 37:58-67.

Chi, G.C, Maier, A.T. \& Gursoy, D. (2013). Employees' perceptions of younger and older managers by generation and job category. Journal of Hospitality Management, 34:42-50.

Collins, A.B. (2002). Gateway to the real world, industrial training: dilemmas and problems. Tourism Management, 23:93-96.

International Journal of Hospitality Management, (2014). Editorial, The need for cross-cultural competence training, 37:A1-A2.

Hein, G.E. (2006). Museum Education. In Macdonald, S. (ed.) A Companion to Museum Studies (pp.340-352), Oxford:Blackwell Publishing.

Hemmington, N. (2007). From Service to Experience: Understanding and Defining The Hospitality Business. The Service Industries Journal, 27(6):2-7.

Kim, H.B \& Park, E.J. (2013). The role of social experience in undergraduates' career perceptions through internships. Journal of Hospitality, Leisure, Sport \& Tourism Education, 12:70-78.

Kim, T.T. \& Lee, G. (2013). Hospitality employee knowledge-sharing behaviors in the relationship between goal orientations and service innovative behaviors. International Journal of Hospitality Management, 34:324-337.

Kim, J.H.G. (2008). Career expectations and requirements of undergraduate hospitality students and the hospitality industry: An analysis of differences. A thesis submitted 
to AUT University in partial fulfilment of the requirements for the degree of Master of International Hospitality Management (MIHM)20-21.

Mistilis, N \& Sheldon, P.J. (2005). Knowledge Management for Tourism Crises and Disasters. Paper Submitted to Best Education Network Think Tank V-Managing Risk and Crisis for Sustainable Tourism: Research and Innovation June 16-19, The University of West Indies Kingston, Jamaica.

Morrison, A. \&O’ Gorman, K. (2008). Hospitality studies and hospitality management: A symbiotic relationship. International Journal of Hospitality Management, 27:214-221.

Nieves, J., Quintana, A. \& Osorio.(2014). Knowledge-based resources and innovation in the hotel industry. International Journal of Hospitality Management, 38:65-73.

Pena, P.I.A., Jamilena, F.M.D. \& Molina, R.A.M. (2013). Antecedents of loyalty toward rural hospitality enterprises: the moderating effect of the customer's previous experience. International Journal of Hospitality Management, 34:127-137.

Shani, A., Uriely, N., Reichel, A. \& Ginsburg, L. (2014). Emotional labor in the hospitality industry: The influence of contextual factors. International Journal of Hospitality Management, 37:150-158.

Sourouklis, C. \& Tsagdis, D. (2013). Workforce diversity and hotel performance: A systematic review and synthesis the international empirical evidence. International Journal of Hospitality Management, 34:394-403.

Walo, M.A. (2000).The Contribution of Internship in Developing Industry-relevant Management Competencies in Tourism and Hospitality Graduates. Masters Thesis submitted at Southern Cross University, Australia.

Yafang, B., Gongyong, F.A .(n.d.). Study on Hospitality Students' Satisfaction towards their Internship: a Case from Hang Zhou, China, pp. 1069-1076. 